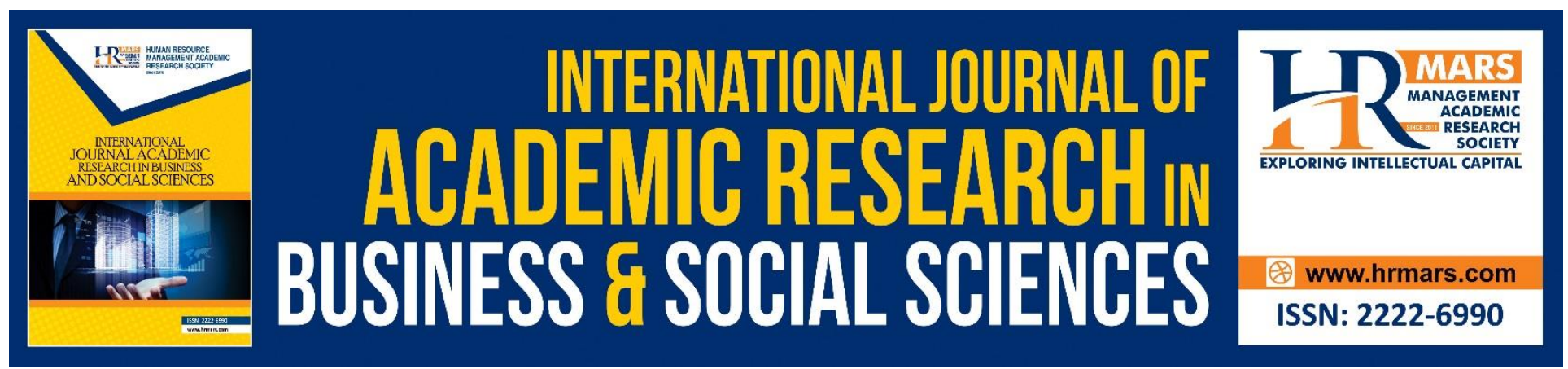

\title{
Students as Agents of Change in School Communities through Strategic Management Approach to Schools
}

\author{
Despoina Androutsou \\ Adamos Anastasiou
}

To Link this Article: http://dx.doi.org/10.6007/IJARBSS/v8-i12/5345

DOI: $10.6007 /$ IJARBSS/v8-i12/5345

Received: 07 Nov 2018, Revised: 17 Dec 2018, Accepted: 28 Dec 2018

Published Online: 29 Dec 2018

In-Text Citation: (Androutsou \& Anastasiou, 2018)

To Cite this Article: Androutsou, D., \& Anastasiou, A. (2018). Students as Agents of Change in School Communities through Strategic Management Approach to Schools. International Journal of Academic Research in Business and Social Sciences, 8(12), 1843-1850.

\section{Copyright: (C) 2018 The Author(s)}

Published by Human Resource Management Academic Research Society (www.hrmars.com)

This article is published under the Creative Commons Attribution (CC BY 4.0) license. Anyone may reproduce, distribute, translate and create derivative works of this article (for both commercial and non-commercial purposes), subject to full attribution to the original publication and authors. The full terms of this license may be seen

at: http://creativecommons.org/licences/by/4.0/legalcode

\section{Vol. 8, No. 12, 2018, Pg. 1843 - 1850}

Full Terms \& Conditions of access and use can be found at http://hrmars.com/index.php/pages/detail/publication-ethics 


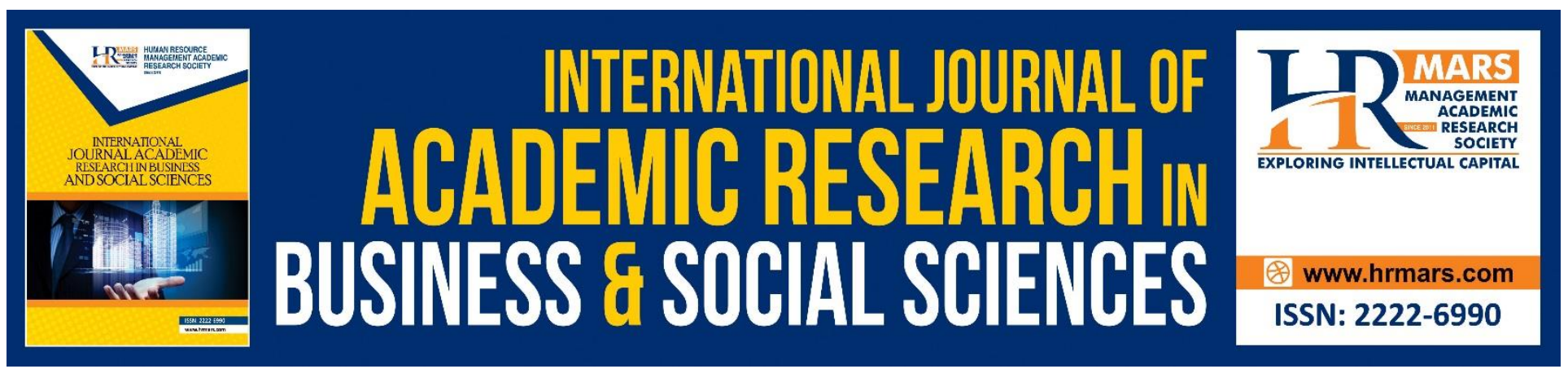

\title{
Students as Agents of Change in School Communities through Strategic Management Approach to Schools
}

\author{
Despoina Androutsou \\ Hellenic Open University, Educational Sciences, Address: Omirou 14, Peraia Thessaloniki, Greece \\ Email: desp.adam@gmail.com \\ Adamos Anastasiou \\ Hellenic Open University, Educational Sciences, Address: Omirou 14, Peraia Thessaloniki, Greece \\ Email: adamosana@gmail.com
}

\section{Abstract}

The article aims at investigating elements concerning school change and how students as integral parts of the school community contribute to the success of the aforementioned issue. Additionally, the article examines how the adaptation of strategic management improves school environment, school performance and fulfils both the academic as well as the organisational mission of the school units. More particularly, the application of school change includes the implementation of specific steps which in turn will guarantee cultivating students' agency, empowerment and greater commitment to participate in creating better social relationships in the school environment resulting in the improvement of the whole the school culture.

Strategic management on the other hand, by implementing the critical elements for effective management along with participation of school members and leadership of administrators could result in enhancing quality of planning, motivating teachers and developing their competence. Leadership can initiate and maintain the strategic management process. All in all, it is of crucial importance that our students will enhance their understanding of organizational behavioural norms and their sense of their role, and value, in the organizational life of the school which could constitute a place where young learners will learn all the necessary skills that will enable them to become successful leaders and to deal with authority.

Keywords: School Change, Strategic Management, Effective School Management, Leadership.

\section{School Change}

Change is something that happens all the time, even if we sit still or do nothing. The difficult thing though is to make these particular changes that persist, endure and in the end will make our lives better. But the starting point in this procedure for all the school communities is to make dramatic 
progress towards the goal of becoming safe, secure and supportive communities for its members. All schools should realistically aim at equipping students with the specific values and beliefs and with the kinds of strong questioning and thinking skills that will serve them well as they find their way into this new century.

As far as changes and school reforms is concerned, the fact that still remains, is that there is not enough follow through or evaluation after the implementation of changes (Fenwick, 2007, Simovska,2004). Maybe it is about time that we start thinking about different things as far as what the real needs of the students are. Consequently, instead of wondering how to raise achievement, we should try to find ways to motivate our students and make them feel excited about learning and exploring. We are only interested in test scores and exam results for entering University gates and as a result we, as parents and educationalists, are actually depriving our children of their own childhood, as they have no time to play and have fun, no time to explore and experiment, no time to 'learn how to learn' by themselves (Cook-Sather, 2002).

The first step in making changes so as to improve education is to recognize that the problems plaguing our schools are rooted in the way our society is organized. We live in a competitive economy where businesses and individuals continually seek advantage and higher profits, whereas our culture glorifies violence in sports, movies, and video games and even on evening news broadcasts (Bowles \& Gintis, 1976).

Under these circumstances, it is not surprising that our school system is designed to sort children out and leave many of them uneducated as schools teach competitive behaviour and social inequality as if they were fundamental law of nature. Just as with the economy, some are rewarded in school, others are punished, and both groups are taught that rewards and punishment are the result of their own efforts (Kohn, 1999). Therefore, education will not be changed in isolation but the efforts to improve schools can be part of a struggle to create a more equitable society and that an important part of our job as teachers and educationalists is to help prepare our young students to participate as active citizens in a democratic society by organizing experiences so that students learn content, social and academic skills, and an appreciation for democratic living.

According to Greene (1993), in order to create democratic classrooms, teachers must learn to listen to student voices as listening allows teachers to discover what students are thinking, what concerns them, and what has meaning to them. When teachers learn to listen, it is possible for teachers and students to collectively search for historical, literary, and artistic metaphors that make knowledge of the world accessible to us. Through this collaboration students could combine critical thinking with creative imagination in an effort to empathize with and understand the lives, minds, and consciousness of all human beings by discovering new questions about the world and ourselves.

\section{How to Plan School Change}

Before deciding which are the specific changes that could lead to school success, it is necessary to follow some particular steps so as to implement school change (Noguera, 2008).

The first step includes establishing ownership of the problems by:

1. Using data to identify areas where change is needed.

2. Providing staff with time to visit successful schools to observe patterns of interaction, teaching and learning. 
INTERNATIONAL JOURNAL OF ACADEMIC RESEARCH IN BUSINESS AND SOCIAL SCIENCES

Vol. 8, No. 12, Dec, 2018, E-ISSN: 2222-6990 @ 2018 HRMARS

3. Soliciting input from stakeholders, students, parents, community.

4. Building sense of community with staff and providing opportunity for discussion of the problems identified.

The second step of implementing change is to develop a specific plan of change by:

1. Forming committees focused on areas where change is needed: discipline, shared ownership, professional development

2. Setting clear, measurable and achievable goals- short, medium and long-term.

3. Implementing rituals, practices and procedures that will serve as the anchor to the new culture.

4. Providing ample opportunity for discussion of the plan, so as to receive input for strengthening the plan.

The third step of changing includes implementing the plan by:

1. Making sure that all the members of the school community understand what is expected of them.

2. Collecting baseline data so as to monitor change over time.

3. Checking in at regular intervals to assess how effectively the plan is being implemented.

4. Getting input from students as well.

Moreover, according to Deshler (2004), organisational changes need readiness, passion, mobilization and implementation so as reach their goals and objectives and enable each school community to move for its current state to a successful future state. The change framework and the components of organisational change are presented in the Figures 1 and 2 that follow:

Figure 1: The change framework (Deshler, 2012: 38)

\section{Change Framework}

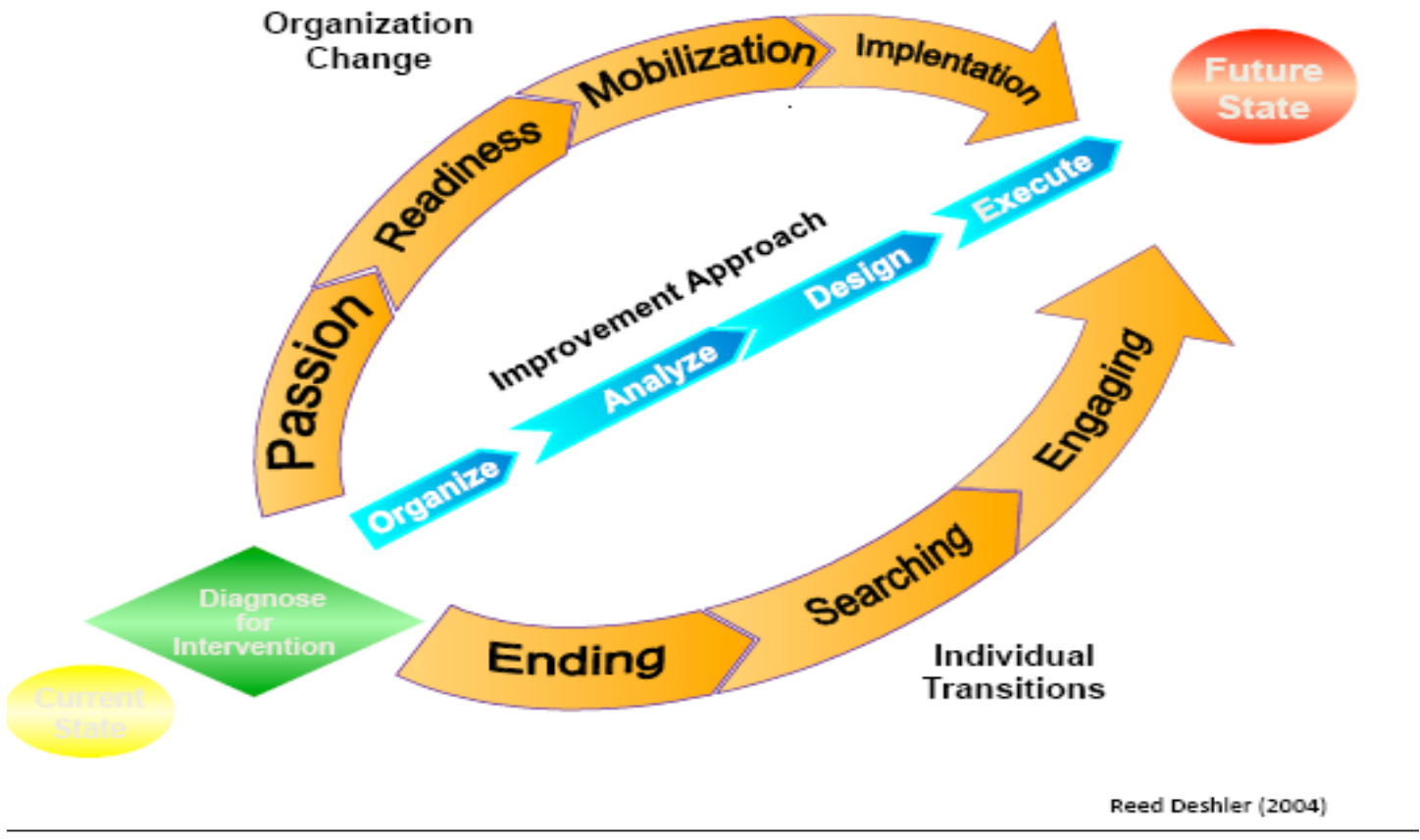

Figure 2: The change framework (Deshler, 2012: 38) 


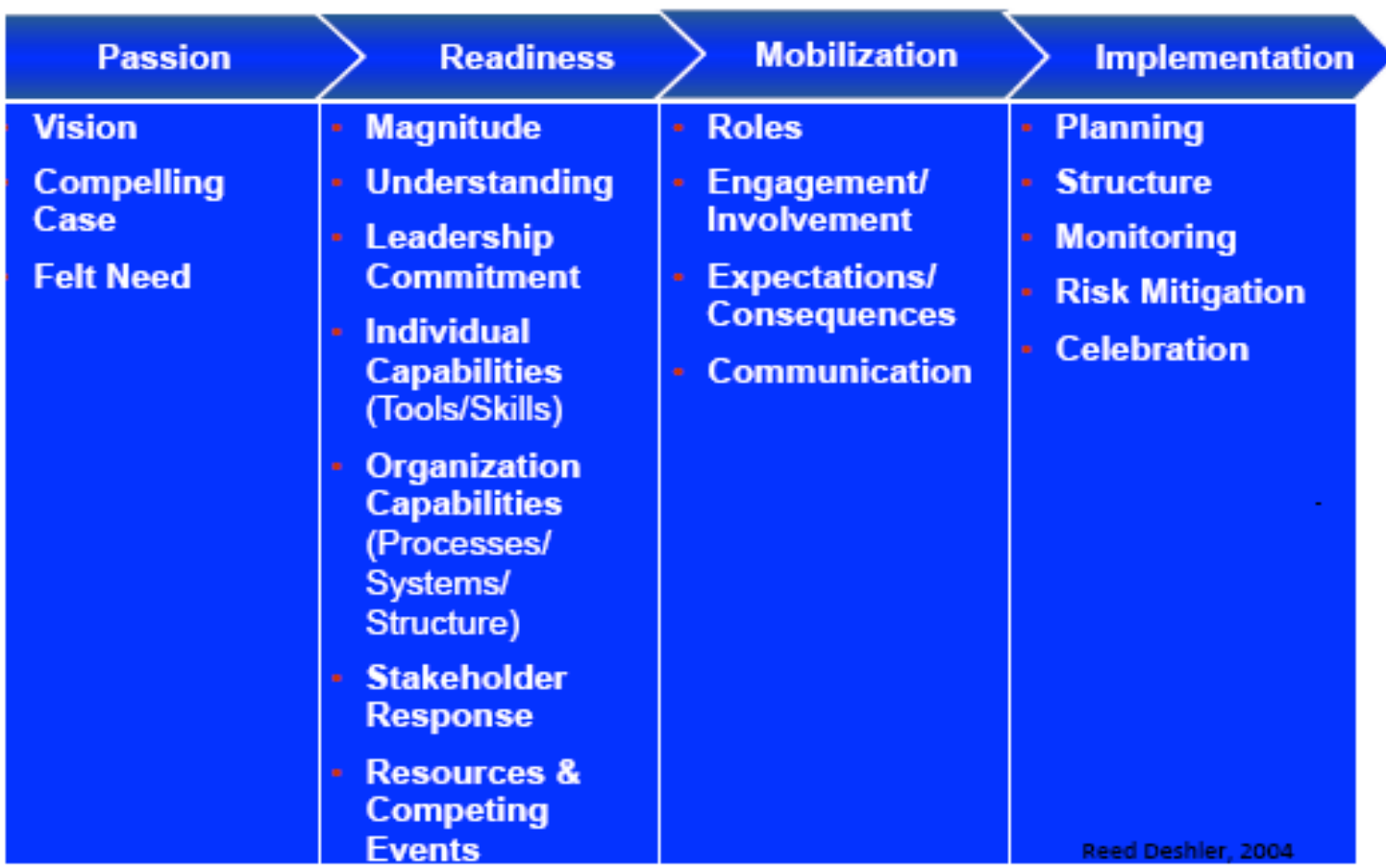

As already mentioned the contribution of students in the efforts to implement changes in the school environment and improve the school culture is of crucial importance. Through the use of surveys, interviews or focus groups, we can solicit inputs from students so as to investigate which areas of teaching-learning need to be changed or improved. To start with, providing opportunities for students to see how academic knowledge can be applied in the real world might lead to the desired results. This application in the real world includes personal development and self-esteem of the young people so as to become independent thinkers and confident individuals. Our students should not be isolated learners, learning facts until the exams are over and then forgetting them, but instead through engagement, they should be helped to form concepts about the world which will in turn enable them to become global-self regulated learners (Otero \& Sparks, 2000).

On the other hand, cultivating students' agency, empowerment and greater commitment to participate could also help in creating better social relationships in the school environment which in turn could result in the improvement of the whole the school culture (Simovska, 2004). Students should be given opportunities to become involved in community service and leadership procedures so as to increase pupils' initiative, critical thinking, open-mindedness, ability to cope with unexpected situations and capability for constructive action. Furthermore, students should be able to participate in school life events through their established student councils, or organise extra curriculum activities and workshops.

Through the aforementioned procedures students will become agents of school change as recipients of introducing a broaden strategic management approach to schools which in turn will contribute to the improvement of the whole school community.

\section{Taking a broader strategic management approach to schools}

According to Cheng (2004), strategic management in school is a process which can keep a school, as a whole, matched appropriately to its environment, improve school environment, improve 
school performance, achieve school objectives, and fulfil school mission. It should include the following sequential components:

Environmental analysis. The internal and external environment which can influence the school is monitored and information is procured and processed for planning.

Systematic planning and structuring. Based on the reflection on the information of an environmental analysis, a course of individual / programme / school actions is predetermined and all the necessary jobs, relationships and resources are arranged for accomplishment of programme / school objectives. Appropriate staffing and directing. Competent people are developed for positions and helped to bring about purposeful actions towards individual / programme / school objectives according to plans.

Constructive evaluation and controlling. By establishing reporting system and performance standards, implementation of plans at the individual / programme / school levels is monitored and performance at all these three levels is evaluated in order to ensure progress towards planned objectives.

Therefore, strategic management process is a cyclic learning process that contributes to continuous improvement and development at the individual, programme / group, and whole school levels. Throughout the process, the critical elements for effective management are participation of school members and leadership of administrators. Participation can enhance quality of planning, motivate teachers and develop their competence. Leadership can initiate and maintain the strategic management process. All the above are presented in Figure 3 that follows:

Figure 3: Strategic Management Process in School (Cheng, 2004: 31)

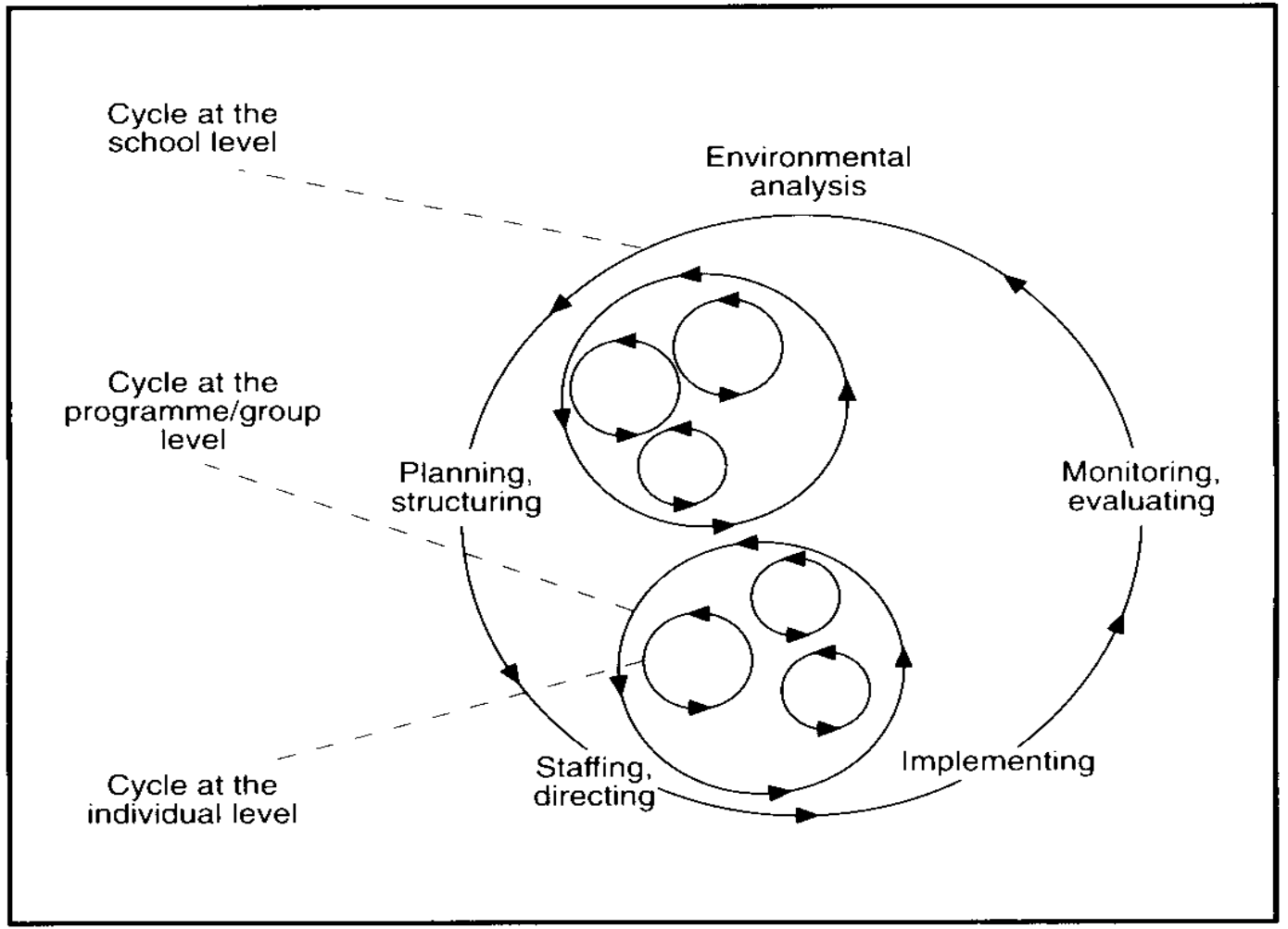


To view the school, as a learning community is to recognise that participation, success, inclusivity and collaboration are important values and ideals for the whole school community. In such a school all the members involved should follow a set of commitments that guide school development and contribute to school success: students are enthusiastically participating in a broad and balanced curriculum; principals (and other institutional leaders) function as educative leaders within the school community; teachers are themselves learners in a community of learners whereas parents are highly encouraged to become actively involved in their children's learning by taking part in all the procedures that constitute them equally responsible participants in school decisions and governance.

The first and foremost challenge so as to make all these changes is to address the very idea that children come to school to learn. Learning is an experience itself and the school community should be held responsible for the learning of values that young learners should possess so as to face future with dignity and optimism. At present school children are made to see the world through language and it is through words the phenomenon of the world is explained to the children, which is fragmented and disconnected from the child's experience of the world. The children need to experience various phenomenon of the world and this enables the development of the cognitive structure, which in turn helps them to understand the processes of society.

In order to start this journey of understanding, young learners should be equipped with values that will enable them to be successful in all fields in their adult life. The list of values includes responsibility honesty, moral courage and friendliness in students. Children should also learn about justice and fairness through sharing their ideas and experiences. Humility, innocence and awe are also fundamental values with which the children embark the journey of learning. Love, care, respect, openness and co-operation will make children feel safe and secure inside the school community.

\section{The 'new changed' school and its characteristics}

Schools as organisations need to possess a number of characteristics and qualities so as to be able to fulfil their goals and purposes and prepare young people for their uncertain future. Since schools constitute complex and complicated organisations because of the expectations laid upon them and of the critical place they have in our society and therefore they need to adopt change strategies that will provide internal stability while moving ahead.

In these 'new' schools deep exploration will go hand-in-hand with high expectations on behalf of all the participants in the teaching-learning procedure. Students' success will be the outcome of an engaging curriculum that fosters a symbiotic integration of head, heart, and hands. The difference though, is that in this specific environment students will also learn a number of other things that will accompany them for the rest of their lives, as they will define much of their organisational behaviour and social identity.

In schools as organisations young learners should be able to grasp the opportunity to learn about how power, leadership, group processes and self-esteem are used in organisations. Most importantly of all, students will enhance their understanding of organizational behavioural norms and their sense of their role, and value, in organizational life of school. Moreover, children will learn how the organisational processes inside the school work, how to belong to a safe environment, and form, protective groups. Schools will also constitute places where young learners 
INTERNATIONAL JOURNAL OF ACADEMIC RESEARCH IN BUSINESS AND SOCIAL SCIENCES

Vol. 8, No. 12, Dec, 2018, E-ISSN: 2222-6990 @ 2018 HRMARS

will learn all the necessary skills that will enable them to become successful leaders, to deal with authority, or even how people control people.

\section{Conclusion}

School change should possess as a crucial priority the aim to equip students with the specific values and beliefs and with the kinds of strong questioning and thinking skills that will serve them well as they find their way into this new century.

Through these procedures the children will have a clear image of what social status means in an organization, whereas at the same time they will be in the position to recognise which kinds of behaviours are 'acceptable' and 'unacceptable' and which are the models of success and failure. The learning of all the aforementioned things is of crucial importance as the picture we develop in our minds of how these processes work inside the school environment affects all our later organizational behaviour. Through the engagement in high-concept, high-touch projects using real-world and realtime applications, students will be immersed in the process of learning, exploring, discussing, designing, reflecting and refining.

As far as skills are concerned, patience, intelligence, observation, curiosity, attention and codification are some of the skills that young learners need to acquire during their school years and this can only be achieved by actually engaging with the real world. There is no doubt that in an openended knowledge quest child learn to be open, spontaneous, intuitive, creative, responsible and experimental.

\section{References}

Bowles, S. \& Gintis, H. (1976). Schooling in capitalist America, Educational reform and the contradictions of economic life. New York: Basic Books.

Cheng, Y. (2004). Effectiveness of Curriculum Change in School. International Journal of Educational Management, 8(3), pp. 26-34.

Cook-Sather, A. (2002). Authorizing students' perspectives: Toward trust, dialogue, and change in education. Educational Researcher, 31(4), pp. 3-14.

Deshler, D. (2012). What Successful Schools Have in Common. (MTSS Symposium, 2012).

Fenwick, T. (2007). Organizational Learning in the 'Knots': Discursive Capacities Emerging in a SchoolUniversity Collaboration. Journal of Education Administration, 45(2), pp. 138-153.

Greene, M. (1993a). Diversity and inclusion: Towards a curriculum for human beings. Teachers College Record, 95(2), pp. 211-221.

Kohn, A. (1999). Punished by rewards: The trouble with gold stars, incentive plans, A's, praise, and other bribes. Boston, MA: Houghton Mifflin.

Noguera, P. (2008). Re-imagining schools: Placing Teaching and Learning at the Centre of Reform. Available on line: www.Gordon ade.blogspot.com/2008/Pedro- Noguera-re-imagine.

Otero, G., Chambers-Otero, S. \& Sparks, R. (2000). Relational learning. Melbourne: Hawker Brownlow.

Simovska, V. (2004). Student Participation-Simulation or Reality? A Vignette from Macedonian Network of Health Promoting Schools. Health Education, 104(3), pp. 163-173. 